\title{
UM JORNALISTA COMBATENTE: \\ Clóvis Moura, Flama e a política cultural do PCB (1951-1952)
}

\author{
A fighter journalist: Clovis Moura, Flama and the PCB's cultural \\ politics (1951-1952).
}

\section{Teresa}

\section{MALATIAN}

(D) tmalatian@uol.com.br

Universidade Estadual

Paulista - UNESP

Franca, São Paulo, Brasil

\section{RESUMO}

Clóvis Moura (1925-2003) tem sido estudado por suas obras mais conhecidas de História e Sociologia, algumas delas hoje com o estatuto de clássico, como Rebeliões da Senzala. No entanto, uma importante dimensão de sua atividade intelectual, a de jornalista, permanece obscura, apesar de relevante. Neste artigo, pretende-se abordar a revista Flama, por ele criada e dirigida na cidade de Araraquara (SP) no âmbito da política de Frente Cultural desenvolvida pelo Partido Comunista Brasileiro (PCB). De duração efêmera (19511952), a publicação merece destaque tanto por seu conteúdo alinhado com o partido como pela relevante rede de sociabilidades intelectuais e políticas construída pelo seu criador e diretor. Um terceiro aspecto referese à repressão policial que motivou, revelada pela análise dos prontuários do DEOPS-São Paulo.

Palavras-chave: Clóvis Moura, revista Flama, imprensa comunista.

\begin{abstract}
Clovis Moura (1925-2003) has been studied by his most known works of History and Sociology, some of them considered today as classics, as Rebellions of Senzala. However, one important dimension of his intellectual activity, as a journalist, remains obscure, even though relevant. On this article the intention is to approach the review Flama, created and directed by him in the city of Araraquara (SP), in the ambit of the Cultural Policy developed by the Brazilian Communist Party (PCB). With ephemeral duration (19511952), the publication de serves be featured by its content lined upwith the party, as well by the relevant intellectuals and politics nets of sociability build by its creator and director. $A$ third aspect refers to the policy repressionthat motivated, accessed in the DEOPS - Sao Paulo files.
\end{abstract}

Keywords: Clovis Moura, Flama review , communist press. 
lóvis Moura (1925-2003), conhecido como historiador e sociólogo, sobretudo pela autoria do clássico Rebeliões da Senzala: quilombos, insurreições e guerrilhas (MOURA, 1959) foi também "homem de imprensa". Em artigos publicados em jornais e revistas, divulgou poesias, resultado de pesquisas e reflexões sobre a sociedade brasileira, sua história e perspectivas, desde os tempos em que residia em sua cidade natal, Amarante (Piauí) e depois em outras localidades do Nordeste, até estabelecer-se finalmente em São Paulo, onde passou a maior parte de sua vida. Trabalhou também na redação de vários periódicos, daí resultando inestimável experiência e facilidade para a escrita, muito oportuna para a produção de sua extensa obra, desde os tempos mais recuados de vinculação aos pequenos jornais até sua inserção na chamada grande imprensa. Atuar simultaneamente na imprensa e na escrita de livros e artigos foi estratégia que lhe garantiu a sobrevivência graças à inserção profissional como secretário de redação ou redator em jornais onde permanecia por vezes no anonimato, porém criava laços e fortalecia sua inserção em redes de sociabilidades intelectuais e políticas amplas. Neste artigo, pretende-se analisar vínculos de Clóvis Moura com o Partido Comunista Brasileiro (PCB), as relações que manteve com a organização partidária e sua linha de atuação na imprensa, com destaque para a revista Flama, publicada em 1951-1952.

O trabalho histórico de uma biografia não se esgota na dimensão individual de um personagem, mas estabelece laços entre passado e presente, entre indivíduo e sociedade, entre o homem e seus contemporâneos. Tomando como referência as obras de Pierre Bourdieu, pode-se afirmar que a linearidade do percurso de uma vida pode ser substituída por laços normativos que conectam o indivíduo a um campo social. Considera-se, pois, o espaço social como

multidimensional, conjunto aberto de campos relativamente autônomos, quer dizer, subordinados quanto ao seu funcionamento e às suas transformações, de modo mais ou menos firme e mais ou menos direto ao campo da produção econômica: no interior de cada um dos subespaços, os ocupantes das posições dominantes e os ocupantes das posições dominadas estão ininterruptamente envolvidos em lutas de diferentes formas (sem por isso se constituírem necessariamente em grupos antagonistas) (BOURDIEU, 1998, p. 153).

\section{Entenda-se aqui por campo uma}

rede de relações objetivas (de dominação ou de subordinação, de complementaridade ou de antagonismo, etc.) entre posições. Compreende ainda códigos de conduta e expressão, problemas a resolver, possibilidades estilísticas ou temáticas a serem exploradas, contradições a serem superadas, rupturas a serem efetuadas (BOURDIEU, 1996, p. 261).

Há, pois, relacionados à vida de cada agente histórico, tensões, decisões, problemas que indicam o campo de possibilidades de uma época, problemáticas pensáveis, 
escolhas realizadas, enfim é como se no percurso de uma vida estivesse também contida a vida de todos que com ele conviveram.

Esses pressupostos permitem neste trabalho a análise da inserção social de Clóvis Moura e o mapeamento de redes de sociabilidade, jogos e práticas políticas, estratégias de inserção/exclusão que denotam os lugares de onde ele produziu sua obra jornalística. Algumas redes de sociabilidade intelectual, que inevitavelmente se entrelaçam com a política, são reveladoras da vinculação de seu pensamento ao marxismo, engajamento que esteve presente ao longo de sua obra de cunho histórico e sociológico. A principal articulação da vida jornalística de Clóvis Moura teve como locus a adesão ao Partido Comunista Brasileiro (PCB) ${ }^{1}$ e posteriormente ao Partido Comunista do Brasil (PC do B), que lhe abriu portas para a colaboração na imprensa periódica partidária e na chamada grande imprensa, como profissional da redação e articulista. Neste artigo, será abordada essa vinculação com o campo político-cultural comunista, principalmente durante o período em que o PCB desenvolveu a estratégia da Frente Cultural.

A dupla inserção intelectuais no mundo das letras e no mundo do jornalismo era bastante comum na segunda metade do século $X X$, e resultava tanto de razões práticas - pois lhes garantia a sobrevivência - quanto da intersecção dos gêneros literários. Como propõem Vaillant e Thérenty em seu trabalho sobre o jornal parisiense La Presse, pode-se constatar não apenas neste caso mas ao longo do século $\mathrm{XX}$, a circularidade entre as formas literárias e as formas de expressão jornalísticas, uma vez que havia coincidência e mesmo sobreposição entre ambas as atividades profissionais na figura do jornalista-escritor ou escritor-jornalista (VAILLANT e THÉRENTY, 2001).

Moura iniciou-se muito jovem como aspirante a jornalista no pequeno jornal $O$ Potiguar, publicação estudantil criada por ele como porta-voz do Grêmio Cívico Literário do Colégio Diocesano Santo Antônio, em Natal (RN), onde fez o curso secundário. Ali publicou em 1939, aos 14 anos de idade, o primeiro texto jornalístico de que se tem notícia, e já revelava na escolha do tema e do título interesse pela história nacional: Libertas que sera tamem abordava a Inconfidência Mineira.

Residiu em Salvador em 1941 por pouco tempo, mas o suficiente para que estabelecesse contatos e vínculos com jovens intelectuais, entre eles Vivaldo da Costa Lima, Aluísio Sepúlveda, Rui e Otto Soledad, Epaminondas da Costa (irmão de Vivaldo), Clóvis Amorim e Isaías Paim. Novo deslocamento da família por motivo de ocupação profissional do pai, funcionário da Receita Federal, o levou a outras paragens, desta vez para Juazeiro, no interior da Bahia, provavelmente em 1942. A mudança de residência não rompeu, entretanto, os vínculos construídos com os intelectuais de Salvador, antes os intensificou mediante correspondência, atividade literária e política. Existem muitos indícios de que os 500 quilômetros de distância entre a capital baiana e a pequena cidade situada no extremo norte do Estado, na divisa com Pernambuco, não abalaram os contatos já estabelecidos. Foi provavelmente por essa época que ocorreu a aproximação de Moura com o PCB, fortalecida sem dúvida na conjuntura do pós-Guerra, quando o partido conseguiu existência legal e grande popularidade, e seu secretário-geral do partido, Luís Carlos Prestes, se sobressaía como grande 
liderança. Certo é que os contatos estabelecidos em Salvador com os intelectuais vinculados ou simpatizantes ao PCB lhe abriram portas para a publicação de artigos e poesias. Ou seja, ele principiou a ter "acesso reservado" ao mundo jornalístico e às páginas de revistas em que publicava resenhas literárias e poesias, como ocorreu com outros jovens escritores aspirantes ao reconhecimento de seus talentos (ROSSI, 2015 e OLIVEIRA, 2009).

Anos depois, residindo na cidade de Juazeiro, Moura persistiu no encaminhamento de sua vida para o jornalismo e fundou em 1949 Jacuba, jornal efêmero, do qual não foram identificados exemplares; porém, indícios sugerem que resultava de contatos mantidos com o PCB. A aproximação do partido já havia motivado sua malsucedida e pouco conhecida candidatura às eleições para o legislativo estadual do Piauí, em 1947, a qual, no entanto, não se concretizou por esse partido, e sim pelo Partido Socialista Brasileiro (PSB), com apoio de Luís Carlos Prestes. Aproximara-se do PSB por ter vínculos familiares com um de seus fundadores, João Mangabeira, que afirmou ser seu tio em depoimento prestado ao Departamento de Ordem Política e Social (DOPS) em São Paulo, décadas depois, mais precisamente em 11 de fevereiro de 1970, quando foi chamado a esclarecer suas atividades políticas ${ }^{2}$. Naquela época das eleições ao legislativo estadual, diversas candidaturas de simpatizantes do PCB foram registradas sob outras siglas; e o PSB, fundado pela fusão de grupos estaduais de tendências de esquerda, abrigava tanto o reformismo cristão como adeptos do marxismo radical. Nas eleições para a Constituinte em 1945 já o partido alcançara grande representatividade ao eleger Prestes senador, além de 14 deputados, todos inscritos no processo eleitoral sob sua legenda.

\section{A Frente Cultural}

O contexto pós-Segunda Guerra Mundial foi marcado pela polarização dos blocos de países capitalistas e comunistas, que além de ameaças de armas nucleares envolveu programas de propaganda cultural por meio de congressos, intercâmbios, discussões sobre cultura e sobretudo atividades editoriais na forma de jornais, revistas e publicação de livros. Conhecida como Guerra Fria Cultural, a dinâmica ensejou no PCB a política de Frente Cultural, projetada para se contrapor aos desdobramentos da Doutrina Truman, que anunciada em 1947 visava enfrentar o avanço do socialismo em países ainda não afetos à influência soviética. A propaganda cultural desenvolvida pelo partido no Brasil reproduzia a pauta definida em nível internacional, e para viabilizá-la foi decisiva a criação de jornais e revistas, sem contar a importante atividade literária de escritores engajados. A estratégia coincidiu com a decretação da ilegalidade do partido e a consequente cassação de seu registro pelo Supremo Tribunal Eleitoral, bem como de seus representantes eleitos após o curto período de legalidade de que desfrutou entre 1945 e 1947. A medida debilitou o partido; porém, apesar da repressão, foi mantida sua vasta rede de jornais e de publicações disseminada em âmbito nacional, alinhada com a política moderada de defesa da união nacional pela consolidação da democracia e pelo combate ao "fascismo". O panorama editorial, de algum modo vinculado ou referido ao partido, indica a grande penetração do PCB entre os intelectuais no período, apesar das prisões de escritores, do fechamento 
de redações e confisco de obras. Por outro lado, evidencia por sua amplitude e persistência a grande valorização que a organização partidária conferia à imprensa e principalmente ao jornal como meio de propaganda de seus ideais, por ser capaz de alcançar grande público (SANTOS, 2016, p. 17).

Na dinâmica das atividades culturais comunistas no Brasil inseriu-se Clóvis Moura após o fim do Estado Novo, tentando conquistar espaço na imprensa partidária. Fracassada a tentativa de atuação parlamentar, em 1947 estabeleceu contato com a revista Literatura, fundada e dirigida por Astrojildo Pereira - que contava em seu conselho editorial com Álvaro Moreira, Aníbal Machado, Arthur Ramos, Graciliano Ramos, Manuel Bandeira e Orígenes Lessa -, com periodicidade irregular embora se apresentasse como mensal. Seu propósito consistia em divulgar debates culturais e literários, levá-los ao povo e promover aliança entre intelectuais, tanto que abrigou escritores de diversas tendências, entre eles os filiados ao PCB, como Jorge Amado, além de outros sem clara filiação partidária (ARBEX, 2012).

Encaminhou à revista uma proposta de publicação, guardada entre os textos recebidos pela revista Literatura no Fundo Astrojildo Pereira/CEDEM, o poema Sangue e manhã nas ruas:

Garcia Lorca, Federico, meu irmão:

hoje as mulheres são assassinadas em praça pública

e as crianças, de braços magros, não tem pão.

Garcia Lorca, Garcia Lorca, meu irmão:

chora o silêncio das correntezas estranguladas, estrelas nascem, rubras e quentes, das lutadoras assassinadas

e os pequeninos não tem pão.

As andorinhas, as pombas brancas, as virgens sofrem. Goteja sangue! gotejam lágrimas sobre as corolas e sobre os mortos. Garcia Lorca, prende em teus dedos este meu canto, este meu canto em que o protesto se faz bandeira que rompe as brumas do coração.

Ai, companheiro, ah, meu irmão!

Se faz protesto da multidão. A madrugada já vem surgindo sobre a mantilha fria da lua, sobre o rocio que molha as flores. $\mathrm{Na}$ rua o sangue se despetala, há vozes vindas do amanhecer, Garcia Lorca brinca com a vida que vem nas dobras das madrugada.

E o trigo louro será o pão

Das andorinhas e das crianças.

Na madrugada haverá pão³. 
O poema engajado, evocativo do herói da Guerra Civil espanhola assassinado em 1936, não foi aceito pelo diretor da revista, mas foi conservado em seu arquivo. Uma preciosa carta endereçada pelo fundador do PCB ao escritor piauiense residente em Juazeiro não deixa dúvidas sobre a busca de Moura por oportunidade de acesso às publicações do partido, nas quais entretanto precisava abrir espaço entre os escritores já consagrados. Ao pleitear publicação de um texto em Literatura, obteve - somente passado um bom tempo e após enviar duas cartas em 30 de janeiro e 21 de maio de 1947 - resposta de Astrojildo Pereira pouco encorajadora de suas pretensões: “Como se pode imaginar, temos sempre colaboração na fila, sujeita ao parecer do conselho de redação. Você deverá portanto aguardar a sua vez”. A recusa foi justificada com o argumento da vida precária da revista, a duras penas mantida em circulação e com a publicação irregular de apenas três números até então. No entanto, a ducha de água fria jogada sobre a demanda do jovem militante não era de molde a afastá-lo totalmente da revista, pois Ihe foi solicitada a tarefa de colaborar na venda de assinaturas:

Grande ajuda poderá v. prestar à revista, conseguindo assinaturas de amigos seus não só em Juazeiro como também em outras localidades onde ela não aparece à venda. Envie-nos uma lista de nomes de prováveis assinaturas e autorize-nos a usar o seu nome como recomendação. Remeteremos a revista a cada um com uma carta nossa propondo a assinatura ${ }^{4}$.

Faltava ainda a Moura capital intelectual ou de consagração que legitimasse sua pretensão junto a Astrojildo Pereira, que sem afastá-lo de todo claramente lhe fez ver a desvantagem em que se encontrava na concorrida busca de reconhecimento como intelectual do partido. Esperava que ele lhe "mandasse notícias".

Em 1949, cada vez mais integrado a um grupo de intelectuais da capital baiana que atuavam no PCB, Moura trabalhou como redator em O Momento, jornal diário publicado em Salvador (MESQUITA, 2003, p. 560) entre 1945 e 1957, com o objetivo de divulgar atividades do partido e chamar leitores para a militância, além de estampar notícias nacionais e internacionais, crônicas e temas destinados a alcançar um público amplo. Nele atuou após o empastelamento ocorrido em 1947, na esteira da repressão que se seguiu à situação do partido na ilegalidade; porém, não permaneceu para vê-lo extinto, pois se transferiu com a família para a cidade de São Paulo em 1950, por razões ainda não conhecidas, provavelmente em busca de inserção profissional.

Ali estabelecido, deu continuidade à atuação na Frente Cultural, que nesta cidade era liderada por Caio Prado Júnior, Villanova Artigas e Arthur Neves. Passou a trabalhar como redator do jornal Última Hora, periódico da chamada grande imprensa, fundado e dirigido por Samuel Wainer, onde permaneceu de 1952 a 1958. Paralelamente, atuou até 1955 como secretário de redação da revista Fundamentos, fundada por Monteiro Lobato e publicada trimestralmente pelo PCB em São Paulo de 1948 a 1955 , sob a direção de Armênio Guedes, Villanova Artigas e Caio Prado Júnior. Abordava temas culturais, os quais correspondiam ao anúncio de tratar-se de "revista de cultura 
moderna”, expressa em assuntos variados. Deixara de ser um principiante noviço, e iniciava um período consistente de inserção como profissional da imprensa nas publicações comunistas.

Além de atuar na secretaria da redação, Moura encontrou em Fundamentos acolhida para sua própria produção e uma interlocução respeitosa, que reconhecia a contribuição que ele poderia dar ao periódico na captação de artigos, expectativa sem dúvida autorizada pelo seu dinamismo e pela rede de sociabilidades comunistas a que ele pertencia. Publicou entre 1952 e 1955 quatro artigos sobre literatura e história, os quais traduziam não apenas suas preocupações da época mas também, e principalmente, pautas do PCB em seu programa anticapitalista, anti-imperialista e de valorização das lutas populares ${ }^{5}$.

O primeiro artigo publicado em Fundamentos versava sobre o cinquentenário de publicação de Os Sertões. Recebeu do editor Villanova Artigas um parecer favorável, além do incentivo ao autor para não só enviar outro artigo, mas também atuar no sentido de buscar colaborações para publicá-las na revista:

Recebemos o artigo que você mandou; está programado para o número 28. Veio mesmo a calhar porque estamos publicando uma série de estudos sobre Euclides. Um deles, de Gonçalves Machado, foi reproduzido em "Jornal de Debates" (título Euclides Socialista).

Dedicar um dos próximos números a Euclides como matéria central é boa ideia. Pergunto se poderemos contar com você para um artigo. Um número sobre Euclides poderia ser por volta de setembro / outubro.

As críticas foram aceitas em geral. Não encontramos realmente uma maneira de comemorar o trigésimo [?] e dormimos com o aniversário de Stalin. Em compensação fomos a única revista a cumprir as deliberações do Conselho Mundial da Paz comemorando Vitor Hugo e Da Vinci. Um dos nossos artigos sobre Da Vinci foi lido na rádio de Moscou no dia do 5.0 aniversário de Leonardo.

Não esqueça de "Fundamentos" e sempre, que possível mande uma colaboração. Não há por aí alguém interessado em assuntos econômicos, café, algodão que queira escrever? Se não for possível conseguir artigos, reportagens sobre situação econômica de certos produtos, condições de exploração de trabalhadores do campo etc...6.

Um último comentário de Artigas na carta de oito de maio de 1952 sugere divergências e zelo por autonomia demonstrado por Moura, provavelmente refratário à disciplina partidária: "O seu direito de criticar ficou intacto; não deixe de escrevernos”. O artigo foi publicado no número 28 da revista, em 1952, com o título de No Cinquentenário de Os Sertões. Quanto ao outro texto, praticamente encomendado por Artigas, parece ter sido Euclides da Cunha e a realidade nacional, publicado em 1954, no número 38. 
O diálogo epistolar com Artigas e a publicação dos artigos sugerem que Moura vinha realizando estudos sobre Euclides e sua obra há algum tempo, em consonância com a política cultural partidária de democratização da cultura para a transformação da sociedade brasileira, a qual visava também a valorização de escritores cujas obras haviam marcado o panorama literário anterior ao modernismo. Nesse sentido, Fundamentos desenvolveu pauta predominantemente literária de orientação antiimperialista, em artigos e ensaios que incluíam temas da atualidade, que a caracterizaram como revista de cultura.

Essa diretriz é visível também no artigo laudatório de Moura sobre José Marti, escrito a propósito do centenário do nascimento do herói cubano das lutas pela independência, coerente com as teses do PCB associadas à luta contra o "imperialismo ianque", que deixava em segundo plano o colonialismo espanhol que se instalara secularmente na ilha. As qualidades de mártir da liberdade e defensor de ideias progressistas de Marti foram lembradas ao lado da revolta dos "homens de cor, composta na sua maioria de escravos e ex-escravos que trabalhavam nos canaviais da ilha e foi esmagada", indício de que o tema das rebeliões da senzala não estava adormecido para seu autor (MOURA, s/d).

O contato com a redação de Fundamentos foi nesse sentido importante também por ter incentivado a correspondência de Moura com o antropólogo baiano Edison Carneiro, que já integrava a equipe de redação da revista e publicou no periódico entre 1950 e 1951 artigos sobre temas de grande interesse para a gestação de Rebeliões na Senzala, que Moura publicaria em 1959. O primeiro deles foi O significado nacional da obra de Arthur Ramos (CARNEIRO, 1950), cuja obra se tornara referência nos debates antropológicos voltados para o estudo do negro na sociedade brasileira. $O$ segundo abordava o pouco conhecido levante dos malês na Bahia de 1835 (CARNEIRO, 1951). Carneiro fazia parte da rede de sociabilidades baianas de Moura, mas não foi encontrado registro de correspondência anterior entre eles. Uma carta enviada por Edison Carneiro logo após a publicação do pequeno texto de uma página sobre os malês esclarece as ligações entre eles, e atribui o crédito da iniciativa do contato a Moura:

Há muito tempo desejava estabelecer contato com você, porque sabia das interessantes pesquisas que você estava realizando, mas nunca escrevi porque uns me diziam que você trabalhava no Momento, outros que você estava catando material na zona do São Francisco?.

Essa missiva constitui mais uma das evidências do diálogo de Moura com o tema da análise do negro na sociedade brasileira que precedeu a publicação de Rebeliões da Senzala, e encontrou em Fundamentos um locus de trocas intelectuais. A tônica da insubordinação escrava motivou comentários de Carneiro colocados em post scriptum na mesma missiva: "O artigo sobre os malês, aparecido em Fundamentos, não tem maior importância. Pediram-me para escrever uma coisa de divulgação, por causa do aniversário, etc. Não tem maior consequência”. 
O direcionamento das atividades de Clóvis Moura na imprensa evidencia a dupla identidade de intelectual e jornalista que se entrelaçavam e preparavam o escritor para voos maiores, de maior responsabilidade. Alcançara, ainda que com limitações, o estatuto de intelectual do partido. Iria fundar sua própria revista.

\section{Flama}

Foi durante o período de militância comunista no jornalismo que Moura e sua irmã Maria do Rosário Meira da Cunha (Merita) fundaram em 1951, na cidade paulista de Araraquara, a revista de cultura Flama. A equipe de redação no primeiro número era constituída por Clóvis (diretor), José de Oliveira e Souza (redator-chefe), Maria do Rosário /Merita (secretária ) e Sidney Schiavon (diretor do departamento artístico). No segundo número, o expediente registra alterações com a inclusão de João Evangelista Ferraz (gerente) e José Magalhães de Castro (chefe de publicidade), enquanto o diretor de departamento artístico foi excluído.

No Arquivo Público Histórico Professor Rodolpho Telarolli de Araraquara encontramse os exemplares dos números publicados entre 1951 e $1952^{8}$, "de Araraquara para o Brasil”, como anunciado em suas capas. A proposta explicitava a pretensão de "ser o veículo progressista e honesto da vida social artística, esportiva e cultural do Município", ainda que lutando contra incompreensão e outros obstáculos inclusive de ordem financeira. Propunha em suas trinta páginas publicar "matéria de interesse geral: reportagens, colaborações de outros pontos do País, noticiário dos acontecimentos nacionais e internacionais", que iria circular e "ser útil em todo o Brasil"9.

Por que Araraquara? A busca dos motivos que teriam levado Moura a fundar uma revista no interior do Estado aponta um dado relevante, a residência de sua irmã e de seu pai na cidade, portanto a presença de uma base de sociabilidades necessária à captação de recursos e à circulação do periódico. Ademais, tratava-se de um município de médio porte que, no início da década de 1950, era destacado na região, formado pelos distritos de Araraquara, Américo Brasiliense, Bueno de Andrada, Gavião Peixoto, Motuca e Santa Lúcia, com 63.388 habitantes, segundo o Censo de 1950 (IBGE, 1951, p. 37). Em franca expansão comercial, abrigava um parque industrial em formação, que aos poucos ia suplantando a atividade agrícola ligada à cafeicultura antes pujante. A fábrica de meias Lupo era o carro-chefe do setor industrial da economia regional, e se expandia para além da modesta empresa familiar criada em 1921. Fábricas da Nestlé, Dianda Lopez e Anderson Clayton despontavam igualmente no cenário de uma cidade em crescimento demográfico e econômico (TELAROLLI, 2003, p. 191).

A análise dos sumários publicados em Flama entre novembro de 1951 e março de 1952 evidencia mais ainda: revela um projeto coletivo desenvolvido por militantes comunistas da região, empenhados na militância intelectual baseada no pressuposto do necessário comprometimento com os ideais do partido. Para isso, a revista foi organizada com uma estrutura de seções definidas, com artigos assinados por Moura e outros intelectuais de pequena projeção na época, porém inseridos no campo comunista. As matérias compreendiam um "Panorama do Mundo", notícias locais e internacionais, e principalmente resenhas literárias e artigos sobre cultura em geral 
(cinema, rádio, esportes, festas populares), que ocupavam o maior espaço da publicação, além de coluna social sobre a cidade. Os temas eleitos pela revista ecoavam a pauta nacionalista do PCB: o pacifismo, a Guerra entendida como o conflito entre Estados Unidos e Coreia, a luta contra o nazifascismo e o Estado Novo, o uso da bomba atômica, o macarthismo. Esses temas eram desenvolvidos juntamente com a valorização da expressão popular por meio de imprensa, concursos de contos, criação de bibliotecas e crítica literária. A criação de "heróis positivos" na seção "Literatura" (Figura 1) ocupava lugar importante nessa estratégia (RIDENTI, 2011, p. 165-166). É de se ressaltar que, com o partido atuando na ilegalidade e mesmo clandestinidade, o comunismo não constituía pauta política explícita, mas assumia uma função pedagógica de informar e formar os leitores por meio da apresentação de aliados e inimigos. Como assinala Mariani, "falar sobre o adversário político sempre foi e será tão importante quanto falar do próprio programa partidário" (MARIANI, 1998, p. 18). Portanto, proibições, censura e silenciamento do PCB impediam a apresentação ostensiva dos ideais comunistas, que eram considerados ameaçadores aos valores estabelecidos na sociedade brasileira.

Para os iniciados nas temáticas preferidas pelo PCB na época, não foi difícil identificar a presença de orientação comunista em Flama. Resenhas de obras de autores comunistas eram ostensivas do posicionamento político de seus editores, mas apareciam também pequenas notícias pouco chamativas por meio das quais eram veiculadas mensagens fortuitas formadoras de opinião. Havia adesão às pautas do PCB, orientadas pelo nacionalismo, anti-imperialismo, defesa da democracia, da liberdade de pensamento e de expressão, e denúncia da exploração entre classes sociais, especialmente da configuração "feudal" dos latifúndios. O artigo "Os cassacos", do redator-chefe José de Oliveira e Souza, ilustra bem essa estratégia, pois no excerto de seu livro homônimo ambientara no arraial de Canudos, no sertão baiano, a exploração de classe a que estavam submetidos os operários que trabalhavam na construção de estradas (SOUZA, 1952). A leitura da história noticiava a revolução democráticoburguesa já ocorrida na Europa, bem como o aparecimento da classe operária na dinâmica da formação da sociedade capitalista. Desde o manifesto de Prestes de $1^{\circ}$ de agosto de 1950, conhecido como o Manifesto da Mantiqueira, o partido adotara uma nova linha mais combativa, que incidia no combate ao imperialismo norte-americano mediante expropriação dos monopólios e latifúndios, além do estabelecimento de controle estatal sobre setores das economia, liberdades democráticas para o povo, promoção da educação obrigatória e gratuita, entre outras metas. A política de união nacional fora suplantada pela linha mais voltada pela busca da tomada do poder, com ampla participação popular.

A revista ecoou essas diretrizes ao conceder destaque ao IV Congresso da Associação Brasileira de Escritores (ABDE), à qual pertencia Clóvis Moura. O evento ocupou grande parte da pauta do noticiário cultural, uma vez que a entidade procurava congregar intelectuais "progressistas" sob o manto da literatura e propunha o desenvolvimento de temas que expressassem engajamento político. Fundada em 1942, no Rio de Janeiro, a associação vinha desde 1945 realizando congressos em diversos estados nos quais as discussões giravam em torno do papel do escritor no mundo contemporâneo e da defesa de princípios democráticos, uma vez que surgira 


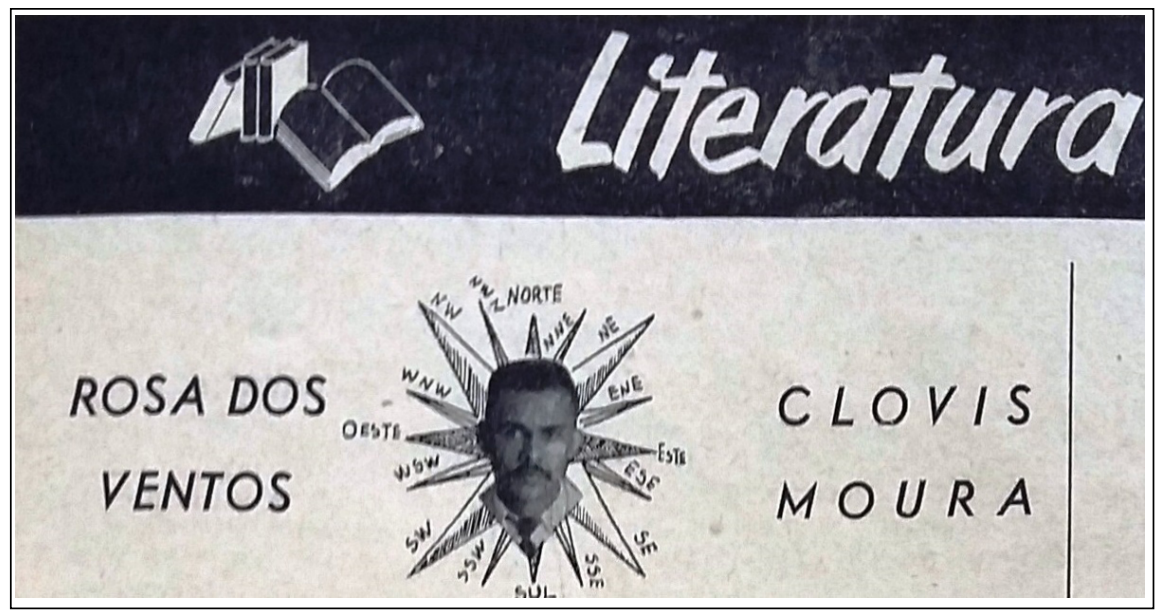

Figura 1. Vinheta da coluna "Literatura" por Clóvis Moura.

em pleno Estado Novo, ao qual apresentou resistência. Integrada por intelectuais destacados nacionalmente, foi presidida de início por Otávio Tarquínio de Souza. Entre os primeiros membros, figuravam Caio Prado Júnior, Aurélio Buarque de Holanda, Sérgio Buarque de Holanda, Astrojildo Pereira, Sérgio Milliet, Antônio Cândido, José Lins do Rego, Graciliano Ramos, Mário de Andrade, Raquel de Queiroz, Aníbal Machado e Monteiro Lobato (MELO, 2011, p. 712, 716 e 726).

As problemáticas específicas relacionadas às atividades profissionais dos escritores, como a defesa dos direitos autorais, logo haviam se mesclado a outras de caráter político no seio da entidade. Progressivamente a ABDE abrigou maior amplitude de debate político entre dois campos opostos, os chamados democráticos e os comunistas. No primeiro grupo, situavam-se liberais, democratas cristãos, social-democratas e comunistas não alinhados com o PCB, entre eles Caio Prado Júnior, Mário Schenberg e outros que haviam adotado postura dissidente em 1942. Esses dilemas correspondiam tanto a um período em que ocorria crescente profissionalização do trabalho intelectual mediante pagamento antecipado de direitos autorais, quanto às grandes mudanças que ocorreram na política nacional na década de 1940. Após a cassação do registro do PCB, a entidade foi de suma importância para o partido no sentido da manutenção de espaço de discussão e difusão de seu programa, ou seja, da atuação da Frente Cultural, que expressava a busca de novas formas de articulação e propaganda no contexto adverso de ilegalidade. O campo de disputa político-ideológica acirrou-se após 1947, com a defesa pelos comunistas do necessário comprometimento de intelectuais e artistas com os ideais do partido (SANTOS, 2016, p. 39-43).

Na Bahia, havia desde o final do Estado Novo um grupo expressivo de filiados à entidade, provavelmente em decorrência da presença de nomes como o de Jorge Amado, que no congresso realizado em 1945, no Rio de Janeiro, presidiu a delegação 
baiana. Ativo em Salvador, o grupo a que Darwin Brandão, amigo de Clóvis Moura, estava vinculado, muito se empenhou na ocasião para que o jovem aderisse à ABDE e se tornasse seu representante e organizador de um núcleo em Juazeiro. Para tal tarefa, foi solicitado a fazer contato com "possíveis sócios", que seriam selecionados segundo um curioso critério, o de serem pagantes: "Não é preciso que a pessoa escreva. Aceitamos como sócios, médicos, advogados, dentistas, professores, etc". ${ }^{10}$ Entre as atividades da ABDE na época estava em andamento o projeto do III Congresso de Escritores em Salvador. Foi realizado em 1950, e dele Moura participou como delegado, provavelmente representando Juazeiro. Ademais, estavam programados congressos regionais visando à expansão da entidade, e Moura era cogitado para encarregar-se pelo que seria realizado em sua cidade, não realizado pois no ínterim ocorreu sua mudança para a cidade de São Paulo.

No ano seguinte, a seção paulista da ABDE realizou o III Congresso Regional, nos dias 7, 8 e 9 de setembro de 1951, com o objetivo de reunir escritores para "discutirem seus problemas profissionais e estéticos, problemas relacionados com as instituições políticas e com a Cultura do povo", como afirmava a notícia publicada em Flama. A divulgação do evento incluiu a Declaração de Princípios aprovada na ocasião em que foram tratados temas específicos e gerais:

defesa da nossa cultura ameaçada por uma subliteratura cosmopolita, decadente e antinacional; a defesa do escritor e dos livros nacionais; a contribuição de São Paulo à cultura brasileira e, finalmente, a defesa da paz mundial, anseio de homens de inteligência do mundo e clima único em que poderá a cultura se desenvolver ${ }^{11}$.

O comparecimento de intelectuais destacados de São Paulo evidencia a dimensão da importância do evento: Afonso Schmidt, Caio Prado Júnior, João Acioli, Galeão Coutinho, Jamil Almansur Haddad, Helena Silveira, Mario Donato e Gonçalves Machado. Mais ainda, uma delegação da entidade em nível nacional presidida por Graciliano Ramos significou o apoio à iniciativa paulista.

Foi de grande relevo na época a declaração de princípios que resultou do encontro: defesa da cultura nacional da influência estrangeira, liberdade de pensamento, repúdio à Lei de Segurança Nacional e à censura prévia, defesa da paz entre Estados Unidos, União Soviética, República Popular da China, Inglaterra e França. Já na ilegalidade, acusado de tendência golpista e antidemocrática, o partido enfrentava onda de prisões de seus militantes e ataques às suas publicações ostensivamente alinhadas, que para sobreviver tiveram que alterar seus títulos. Entre eles, Tribuna Popular do Rio de Janeiro passou a ser denominado Imprensa Popular e Hoje, e de São Paulo teve seu título substituído por Notícias de Hoje.

O envolvimento de Moura com a ABDE resultou em intensa divulgação de notícias sobre a entidade e suas atividades, de pequeno alcance local; pois, afinal, apesar de atender aos interesses partidários, teria como leitores apenas um público restrito. Paralelamente, a revista atendeu aos princípios que a ABDE postulava e manteve uma 
seção de literatura intitulada "Rosa dos Ventos", em que eram distribuídas resenhas e críticas literárias ora laudatórias de escritores afinados com o ideário comunista, ora demolidoras daqueles que não abraçavam igual opção política. Com seu retrato colocado no centro da rosa dos ventos que encabeçava a seção, ele irradiava a todos os pontos cardeais os princípios que abraçara na política e na literatura, defendidos também pela revista Seiva, mensário de cultura editado na cidade de Salvador, cuja propaganda discreta inseriu nas páginas de Flama. Aos vinte e seis anos de idade, Moura instalara nas páginas inflamadas de combatividade um tribunal de escritores que teve curta duração, o suficiente para que exprimisse por meio da crítica literária sua visão de mundo maniqueísta. Além disso, publicava poesias e excertos de diversa extração para ilustrar suas teses.

Por meio dessa pauta compartilhada, Moura expressou aderência à revista Fundamentos e aos intelectuais que nela divulgavam seus textos, mas sobretudo com a proposta de um periódico de cultura afinado com a ABDE. Desde o Manifesto de Agosto de 1950, lançado por Prestes, o partido enfatizava o valor do intelectual comprometido com a transformação social, legitimado pela adesão aos chamados interesses populares. A distinção entre os intelectuais legítimos e os pseudo-intelectuais (a serviço do imperialismo e das forças reacionárias) pautava o alinhamento comunista, e a revista Fundamentos em que Moura mantinha uma inserção tornou-se grande propagadora dessa categorização. Em tal perspectiva, distinguia-se entre a cultura nacional, a verdadeira, e a antinacional, vinculada ao imperialismo (SANTOS, 2016, p. 34).

A tomada de posição de Moura em Flama em relação aos seus pares de Fundamentos reforçou seu reconhecimento como intelectual do partido. Ao fazer opções de crítica literária, expressava por meio dos textos vínculos com a proposta de julgamento dicotômico dos autores nacionalistas versus antinacionalistas. Sua revista constituía um elo na cadeia de disputas intelectuais próprias do período e do meio.

Entre os autores louvados, Afonso Schmidt, jornalista e romancista, diretorresponsável e redator-chefe de Fundamentos entre 1948 e 1955, ocupou lugar destacado não apenas por suas qualidades literárias mas também pela biografia, já que em decorrência de sua "coragem cívica" havia sido processado por "crime de opinião”. O mesmo critério norteou a notícia sobre a expulsão de Pablo Neruda da Itália e a denúncia dos fascistas como responsáveis pela medida ${ }^{12}$. O poeta chileno exilado na Europa mobilizava solidariedade internacional pela condição de militante do Partido Comunista chileno. Monteiro Lobato, fundador de Fundamentos, embora já falecido em 1948, alguns anos antes da fundação de Flama tornara-se um símbolo do nacionalismo, e foi lembrado por ter tido obra apreendida pela polícia. A exploração do homem nordestino na epopeia de Canudos, outro tema recorrente na pauta das publicações da Frente Cultural do PCB, foi também associado a Lobato, enaltecido principalmente por ser considerado o criador da literatura infantil e por ter tratado de "problemas fundamentais de nosso povo", como a exploração do ferro e do petróleo.

Em contrapartida, e por razões ignoradas, Graciliano Ramos, apesar de ser um dos editores de Fundamentos e de seu enorme prestígio na literatura e na política, foi apenas mencionado como presidente da ABDE nacional. 
No rol dos autores desqualificados encontrava-se Vasconcelos Maia com sua obra Contos da Bahia. O contista baiano, autor de Fora da vida - aliás avaliado positivamente - decepcionou Moura, que o interpretou como autor "pequeno burguês", que criara na obra resenhada personagens de idêntica extração social. Ao opinar sobre o contista, Moura aproveitou para expor seu ponto de vista sobre a responsabilidade do escritor: "O escritor é aquele elemento que, dentro da sociedade, tem a sensibilidade mais desenvolvida e capaz de expressar esteticamente os grandes acontecimentos do seu tempo, a linha central da evolução de determinado período". E, para isso, deve "estudar novas teorias causadas pelas classes em ascenso". Não escapou igualmente à sua vigilância doutrinária o autor Mário Donato, tachado de "corifeu existencialista", defensor de uma filosofia "anti-humana, reacionária, depravada", isto é, o existencialismo (MOURA, 1951, p. 20).

Mário Donato recebeu condenação por seu recém-publicado "livro dissolvente", Galatéia e o Fantasma. A crítica de Moura traçou uma continuidade entre a obra resenhada e a Presença de Anita, que esse autor publicara em 1948, provocando grande celeuma pelo seu conteúdo erótico, e vinha de ser filmado em 1951. A crítica extremamente agressiva de Moura ao livro e ao autor retoma surpreendentemente os argumentos moralistas da Igreja Católica, que igualmente condenara autor e obra:

\begin{abstract}
Explora o autor o mórbido e o escabroso para fins sensacionalistas, desligando-se assim daqueles escritores que, em nosso país, durante todo o transcurso de sua história literária, vem procurando retratar com honestidade e o realismo a situação econômica e social de nosso povo e imprimindo às suas obras um fundo conteúdo nacional e popular “(...) assimilando o que há de mais condenável e negativista em certos autores estrangeiros, cai para o pornográfico como recurso literário, copiando toda a putrefação daqueles escritores que, por injunções estranhas à vontade de nosso povo, hoje estão sendo traduzidos e privilegiadamente apresentados como o que existe de mais 'avançado' em matéria de novelística no mundo" (MOURA, 1951, p. 20).
\end{abstract}

A cartada final foi o veredito radical sobre a obra avaliada segundo os valores já assumidos pela revista: livro "inteiramente desligado dos problemas do homem brasileiro, falso", que "não passa do mais deslavado folhetim de segunda ou terceira categoria". (idem).

Outros temas da pauta revelam a orientação nacionalista do periódico: a reação anti-imperialista e nacionalista no Egito, e o cinema infantil dominado pelos filmes de Hollywood. Evidentemente, havia que fazer concessões para tornar a revista palatável e insuspeita aos olhos do grande público não comunista: o primeiro número (Figura 2) trazia na capa em fundo azul uma foto inócua do Parque Infantil de Araraquara, enquanto os números 2/3 (Figura 3) traziam na capa uma imagem evocativa do Natal, "data máxima da cristandade", e os números 4/5 (Figura 4) uma foto alusiva ao Carnaval, afagos ao público leitor que importava conquistar. 


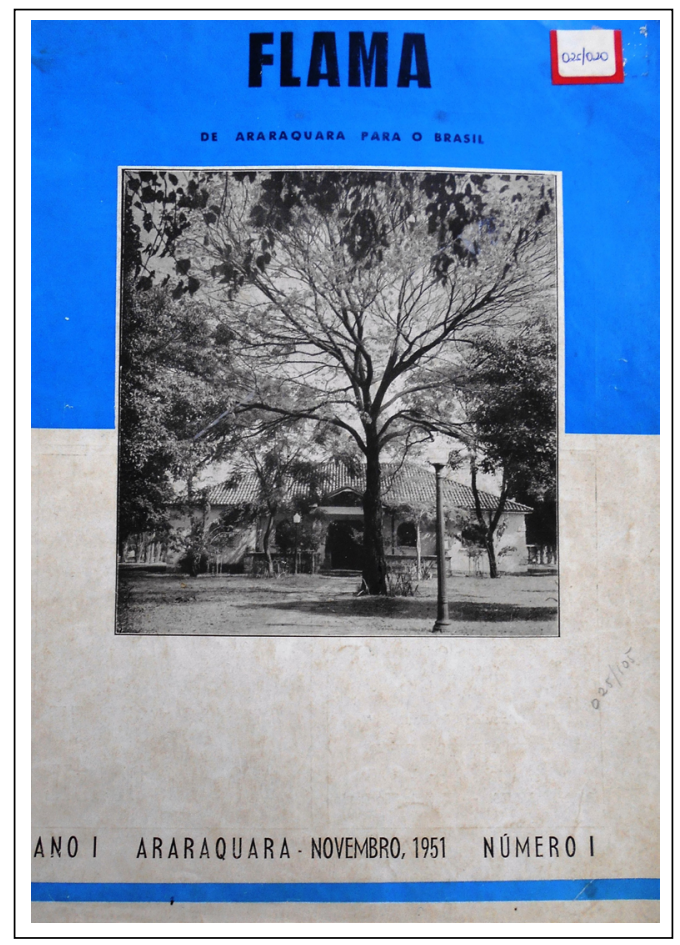

Figura 2. Capa do número 1 da revista Flama.

Chama a atenção o engajamento da revista na campanha nacionalista em defesa do petróleo com o espaço ocupado pela notícia sobre a posse da nova diretoria do Centro Paulista de Estudos e Defesa do Petróleo na Economia Nacional, realizada no salão do Sindicato dos Bancários da capital do Estado. A extensa lista dos presentes incluía o general Leônidas Cardoso (presidente da entidade), outros militares, sindicalistas e intelectuais, como o acadêmico Fernando Henrique Cardoso, Caio Prado Júnior, a viúva de Monteiro Lobato13. Estava no auge a campanha polêmica que precedeu a criação da Petrobrás, no bojo das campanhas nacionalistas de diversos matizes políticos que entre 1952-1953 reivindicavam medidas protecionistas para o petróleo, ferro, manganês, entre outros recursos naturais.

São desconhecidas as relações de Moura com o Comitê Central do PCB ou outras instâncias dessa organização partidária; portanto, fica em suspenso a elucidação de um hipotético apoio financeiro para sua publicação. Para manter financeiramente a revista, ele sem dúvida contou com a captação de propaganda comercial paga, presente em abundância nas páginas do primeiro número. A cidade acorreu com anúncios de casas comerciais de todo gênero, como a fábrica de meias Lupo (já era destacada na época), que permitiam a esperança de que a empresa jornalística 


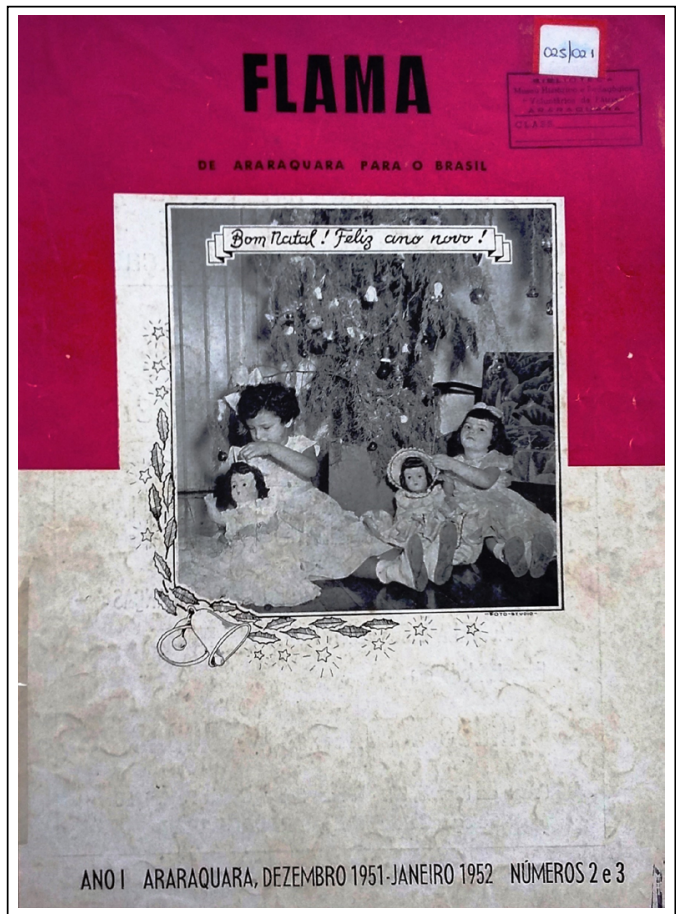

Figura 3. Capa dos números $2 / 3$ da revista Flama.

se manteria do ponto de vista financeiro. Porém, a captação de recursos parece ter sido insuficiente até mesmo no âmbito do partido, pois Moura, logo após a saída do primeiro número, acionou a rede de sociabilidades comunistas na tentativa de obter apoio partidário junto ao amigo Jorge Amado ${ }^{14}$, que na época do lançamento da revista residia em Praga (1950-1952), exilado após ter sido expulso da França em decorrência de suas atividades políticas. O pedido foi frustrado pela negativa do romancista baiano, conforme carta datada de São Paulo, março de 1952, plena de compreensíveis despistamentos sobre sua residência e contatos, em que dizia não ter recebido os exemplares da publicação enviados por Moura, que denominou repetiu a expressão de Moura - como "bandeirante baiano nas terras de São Paulo":

Não posso, pelo menos por enquanto, mandar chover maná sobre as páginas pagas de sua revista, por uma razão muito simples: nada tenho programado para o interior de S. Paulo, a não ser anúncios de automóveis (Mercedes-Benz) para jornais. Além [sic], Araraquara nunca existiu, nunca foi descoberta. Agora sim, com a inspiração bandeirista do baiano, é capaz que venha a ter alguma importância futura ${ }^{15}$. 


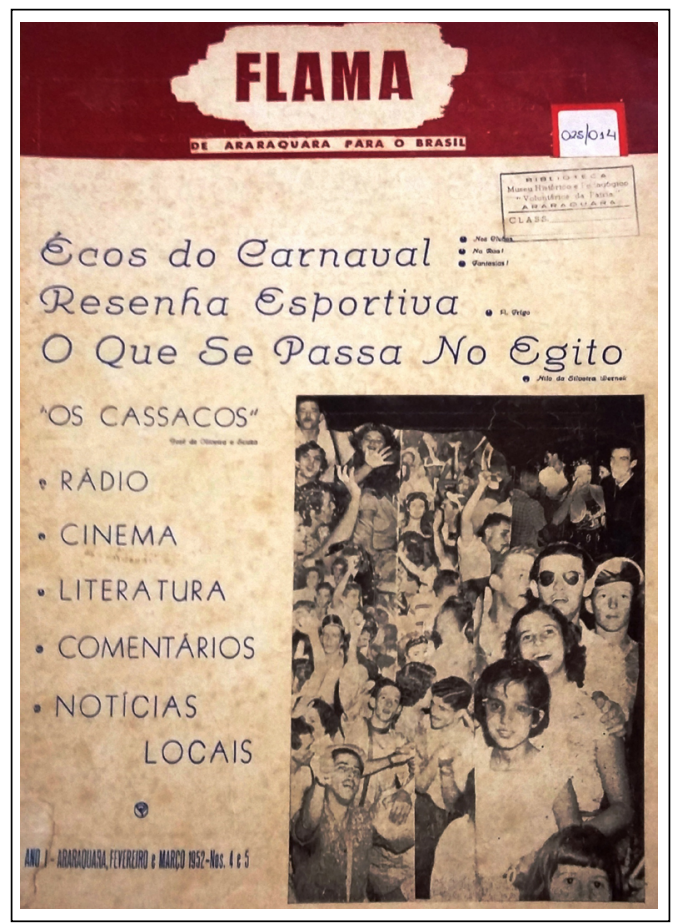

Figura 4. Capa dos números $4 / 5$ da revista Flama.

Ou seja, enquanto convivia com a mais seleta intelectualidade mundial em seu exílio parisiense e posteriormente em países socialistas, Flama lhe parecia obra insignificante, de alcance restrito, editada em uma pequena e obscura cidade do interior paulista, e portanto não considerava importante ou possível promovê-la. Tanto que, apesar de manterem correspondência ao longo de anos, Moura não foi sequer mencionado pelo escritor baiano nas reminiscências das sociabilidades intelectuais dessa época, publicadas posteriormente em Navegação de Cabotagem (AMADO, 1992, p. 105-106).

A amizade epistolar entre Jorge Amado e Clóvis Moura está documentada a partir de 1952, precisamente desde a carta que indica contatos anteriores amistosos: "Não li o poema publicado no Hoje. Mas em compensação o Vasconcelos tem me visitado e não raro falamos a seu respeito". E, mais ainda, aprovava os esforços de Moura na elaboração do livro sobre as rebeliões da senzala, tema que lhe era de certo modo obscuro: "acho-o uma necessidade. De fato, balanceando os poucos informes que tenho da matéria (li um pouco de história, embora não pareça) não me consta nada a respeito de"16. O romancista alcançara tal projeção no campo da cultura comunista, que fora agraciado em 1951 com o prêmio Stalin, e constituía referência importante 
na rede de sociabilidades intelectuais de Clóvis Moura, não apenas por possibilitar talvez a captação de recursos, mas principalmente por seu engajamento intelectual e político na militância comunista. A recusa não rompeu os vínculos entre os dois camaradas pois é de autoria de Jorge Amado o prefácio da primeira edição do livro de poesias de Moura, O espantalho na feira, publicado em 1961 (MOURA, 1961).

O Conselho Mundial pela Paz, entidade internacionalista fundada em 1949 pelo governo soviético, reunia simpatizantes da esquerda de tendências diversas e pautava também a revista Flama inclusive com a referência a Jorge Amado, que era seu membro destacado e havia publicado uma obra específica sobre o tema, Mundo da Paz, posteriormente renegada pelo seu autor, quando se distanciou o stalinismo, por excessivamente colada às diretrizes do partido. Flama ecoou essa pauta, que se manifestava por meio de organizações diversas, entre elas Movimento Nacional pela Proibição de Armas Atômicas (1950) e Congresso do Movimento Brasileiro dos Partidários da Paz (1951), além do referido Conselho que visava denunciar principalmente a Guerra da Coreia (1950-1953) e o imperialismo norte-americano. O conflito despertava a convicção da iminência da Terceira Guerra Mundial, e a aliança entre Brasil e Estados Unidos sinalizava a possibilidade de formação de um corpo expedicionário brasileiro.

De duração efêmera, Flama logo atraiu a atenção dos órgãos da repressão no contexto dos revezes sofridos pelo PCB e da radicalização de sua linha política a partir de 1950. Não admira que, externando as principais campanhas do partido na época, a revista não tenha passado incólume perante a censura. Mas o prontuário Clóvis Steiger de Assis Moura ${ }^{17}$ revela que a publicação somente se tornou objeto de suspeita e investigação em 1952, quando a Secretaria de Segurança Pública de São Paulo localizou o editor e o fichou como comunista. Na verdade, a investigação ocorreu no âmbito de uma determinação do delegado auxiliar do DOPS (Departamento de Ordem Política e Social) ao delegado de polícia regional de Araraquara, em início de junho de 1952, para que realizasse "investigações reservadas nessa cidade, a fim de averiguar quais os elementos de mais destaques que se dedicam às atividades comunistas". A investigação estendeu-se à Bahia, de onde veio a informação de ser Moura "leader comunista", secretário do comitê municipal do PCB em Juazeiro e candidato de Prestes à Câmara Federal em 1947, pela legenda do PSB, cujo registro foi cassado pelo Tribunal Eleitoral Regional ${ }^{18}$. Foi identificado em 11/06/1952, por meio de relatório reservado da Divisão de Informações, que informava também ser a revista por ele dirigida "de fundo de caráter comunista" 19 . Clóvis e Maria do Rosário foram classificados como "elementos ali conhecidos e tidos como comunistas em Araraquara"20. Ademais, a investigação estendeu-se ao gerente João Evangelista Ferraz, reconhecido também como comunista e relacionado com Hermes Valente, "velho militante comunista" da cidade ${ }^{21}$. Desde então, Moura passou a ser monitorado em razão de sua proximidade do $\mathrm{PCB}^{22}$, em outros termos "mantido em constante vigilância com relatório" 23 .

A malha da investigação estendeu-se à família Moura, e foi por meio dela constatado serem ambos filhos de Francisco de Assis Moura, funcionário da Recebedoria de Rendas, todos originários da Bahia e residentes em Araraquara. Merita trabalhava também 
nessa repartição pública federal, “lugar este arranjado para ela pelo próprio chefe da referida repartição federal”. A investigação esbarrou, assim, em um funcionário federal que provavelmente era reputado idôneo e alheio à doutrina comunista. Tanto que a investigação não prosseguiu com a costumeira busca e apreensão pois, segundo os agentes encarregados, o delegado da Polícia Regional os dissuadira, dizendo que "seria tempo e trabalho perdido, porquanto nada iríamos encontrar, pois o mesmo traz constantemente os elementos vermelhos ali residentes em observação. Adiantou-nos ainda aquela autoridade que os mesmos estão quietos e fora de atividade", ou seja, não atuavam no meio sindical, que despertava muito maior interesse da polícia pois o PCB, em aliança tácita com o PTB, a partir de 1952 intensificara sua atuação em movimentos grevistas. No Estado de São Paulo, as atividades foram mais intensas nos sindicatos têxteis e metalúrgicos, que em Araraquara eram de maior peso.

Duas outras informações relevantes surgem no documento: a ausência de Clóvis Moura na cidade - indício de que provavelmente continuava residindo na capital do Estado -, e a afirmação de que "não exerce profissão alguma”, ou seja, o jornalismo não era considerado profissão pelos órgãos policiais ${ }^{24}$. Foi incorporado ao seu prontuário um exemplar do primeiro número da revista; porém, na ocasião, ela já deixara de circular após publicar apenas cinco números, entre 1951 e 1952, os quais saíram em três volumes, provavelmente em decorrência de dificuldades financeiras.

Encerrada a iniciativa de uma revista cultural que deveria circular no interior do estado, Moura permaneceu atuante na rede de publicações do PCB como redator e chefe de reportagem do jornal Notícias de Hoje entre 1953 e 1954, tanto que teve seu aniversário registrado pela redação do jornal :

Aniversaria hoje o nosso companheiro de redação Clóvis de Moura, jovem talentoso, estudioso dos problemas de nossa história, poeta de recursos, de reputação firmada no seio da intelectualidade de vanguarda, Clóvis é ao mesmo tempo um combativo homem de imprensa, que se colocou a serviço das lutas patrióticas ${ }^{25}$.

Os "ecos do aparecimento de Flama", segundo a revista divulgou, foram registrados nos jornais O Estado de S. Paulo, da capital, de 18/12/1951 e Correio de São Carlos, que circulava na cidade vizinha a Araraquara ( $\left.n^{\circ} 2-3\right)$. Em suma, pode-se afirmar que ela foi provavelmente o último vínculo de Clóvis Moura com a imprensa do PCB antes de trabalhar em 1959 como redator nos Diários Associados (Diário da Noite e Diário de São Paulo) dirigidos por Assis Chateaubriand. Nela exerceu, por meio da proposta de uma revista de cultura, a missão de informar aos leitores e obter sua credibilidade para a pauta do partido na época. Com a estratégia de divulgação do discurso "oficial" do PCB, ainda que reduzido a uma vulgata, a revista Flama cumpriu seu papel sobretudo doutrinador, pois o espaço para discussão ou reflexão era praticamente inexistente. 


\section{Referências}

AMADO, Jorge. Navegação de Cabotagem. Apontamentos para um livro de memórias que jamais escreverei. Rio de Janeiro: Record, 1992.

ARBEX, Luciana Bueno Marta. Intelectualidade brasileira em tempos de Guerra Fria: agenda cultural, revistas e engajamento comunista. São Paulo: Dissertação de Mestrado, USP/FFLCH, 2012.

BOURDIEU, Pierre. O poder simbólico. 2. ed., Rio de Janeiro: Bertrand Brasil, 1998. . As regras da arte. São Paulo: Companhia das Letras, 1996.

CARNEIRO, Edison. O significado nacional da obra de Arthur Ramos . Fundamentos, São Paulo, n. 11, janeiro de 1950, p. 13-17.

O levante malê de 1835. Fundamentos, São Paulo, n. 18, maio de 1951,

p. 15.

IBGE/Conselho Nacional de Estatística. Anuário Estatístico do Brasil. Rio de Janeiro, 1951.

MARIANI, Bethania Sampaio Correa. O PCB e a imprensa: os comunistas no imaginário dos jornais ( 1922-1989). Rio de Janeiro: Revan; Campinas: UNICAMP, 1998.

MELO, Ana Amélia de Moura Cavalcanti. Associação Brasileira de Escritores: dinâmica de uma disputa. VariaHistória, Belo Horizonte, v. 27, n. 46, jul./dez.2011, p. 711-732.

MESQUITA, Érika. Clóvis Moura e a sociologia da práxis. Estudos Afro-Asiáticos, ano 25, n. 3,2003, p. 557-577.

MOURA, Clóvis. O espantalho na Feira. São Paulo: Fulgor, 1961. Apresentação de Jorge Amado.

. No cinquentenário de Os Sertões. Fundamentos, São Paulo, n. 28, 1952.

n. 38,1955, p. $27-36$.

Euclides da Cunha e a realidade nacional. Fundamentos, São Paulo,

p. 23-25.

. José Marti, herói do povo cubano. Fundamentos, São Paulo, s/d,

.Rebeliões da Senzala: quilombos, insurreições e guerrilhas. São Paulo: Zumbi, 1959.

. Rosa dos Ventos. Flama,1951, ano 1, n. 1, p. 18.

n. 40, 1955.

A situação do Brasil como Nação Soberana.Fundamentos, São Paulo, 
OLIVEIRA, Fábio Nogueira de. Clóvis Moura e a sociologia da práxis negra. Niterói, Dissertação de Mestrado, UFF, 2009.

RIDENTI, Marcelo. Jorge Amado e seus camaradas no círculo comunista internacional. Sociologia \& Antropologia, UFRJ, v. 1, n. 2,2011, p. 165-194.

ROSSI, Gustavo. O intelectual feiticeiro. Edison Carneiro e o campo de estudos das relações raciais no Brasil. Campinas: Ed. UNICAMP, 2015.

SANTOS, Eduardo Oliveira. Intelectuais comunistas e a revista Fundamentos: afirmação e atenuações das diretrizes partidárias (1948-1955). Dissertação de Mestrado, Programa de Pós-Graduação em História, UFRRJ, 2016.

SOUZA, José de Oliveira e. Os Cassacos. Flama, ano 1, n. 4 e 5, 1952, p. 11.

TELAROLLI, Rodolpho. Para uma história de Araraquara (1800 a 2000). Araraquara: UNESP, FCL, Laboratório Editorial, 2003.

VAILLANT, Alain e THÉRENTY, Marie-Ève. 1836 : I'an 1 de l'Ere médiatique. Paris: Nouveau Monde Éditions, 2001.

\section{Notas}

1 Fundado em 1922 como Partido Comunista - Seção Brasileira da Internacional Comunista, denominação posteriormente encurtada para Partido Comunista do Brasil com a sigla PCB, que se manteve até 1961. Em 1961, passou a denominar-se Partido Comunista Brasileiro, diferenciando-se assim do PC do B.

2 Termo de declaração na Delegacia de Ordem Política em São Paulo, 11/02/1970. Prontuário 81.327. APESP.

3 Cx 11, Pasta 4, ARCH A 2, 7 (3), Fundo Astrojildo Pereira/CEDEM/UNESP.

4 Carta de Astrojildo Pereira a Clóvis Moura, Rio de Janeiro, 15 de novembro de 1947. Fundo Clóvis Moura, CEDEM/UNESP.

5 Revista Fundamentos. Fundo Fúlvio Abramo/ CEMAP/ CEDEM/UNESP. Não foram localizados todos os números da revista, portanto o acesso aos textos se fez por meio dos originais guardados neste arquivo.

6 Carta de Villanova Artigas a Clóvis Moura, São Paulo, 8 de maio de 1952. Fundo Clóvis Moura, CEDEM/ UNESP.

7 Carta de Edison Carneiro a Clóvis Moura, Rio de Janeiro, 17 de julho de 1951. Fundo Clóvis Moura, CEDEM/UNESP.

8 Foram publicados os números referentes ao ano I, a saber, número 1 (novembro de 1951), 2 e 3 (dezembro de 1951 e janeiro de 1952) , 4 e 5 (fevereiro e março de 1952), reunidos em três volumes. O artigo sobre José Marti não foi localizado nos volumes disponíveis à consulta; o acesso se deu aos originais arquivados no CEDEM.

9 Apresentação. Flama, Araraquara, n.1, novembro de 1951, p. 1. A revista era anunciada ao preço do número avulso de cinco cruzeiros e assinatura de quarenta e cinco cruzeiros.

10 Carta de Darwin Brandão a Clóvis Moura, Salvador, 4 de dezembro de 1948.CEDEM/UNESP. 
11 III Congresso Paulista de Escritores. Flama, ano I, n. 1, 1951, p. 20.

12 Chacais da cultura. Flama, ano I, n.1, 1951, p.2 .

13 São Paulo em defesa do Petróleo, Flama, ano I, n. 2-3, 1951,p.5.

14 Jorge Amado (1912, Itabuna-Salvador, 2001), eleito membro da Assembleia Nacional Constituinte por São Paulo, sob a legenda do PCB, em 1945, onde foi autor do projeto da lei que assegura direito à liberdade de culto religioso. Na época da publicação da revista Flama, era autor de renome internacional, graças à publicação de O País do Carnaval (1931), Cacau (1933), Suor (1934), Jubiabá (1935), Mar Morto (1936), Capitães da areia (1937), A estrada do Mar (1938), ABC de Castro Alves (1941), O cavaleiro da esperança (1942), Terras do Sem-Fim (1943), São Jorge dos Ilhéus (1944), Bahia de Todos os Santos (1944), Seara Vermelha (1946), O amor do soldado (1947) e O mundo da paz (1951). Ainda não havia se desencantado com o stalinismo, o que aconteceu logo depois, quando se afastou do partido sem deixar de ser comunista.

15 Carta de Jorge Amado a Clóvis Moura, S. Paulo, março 1952. Fundo Clóvis Moura, CEDEM/UNESP.

16 ldem.

17 Prontuário n. 81.327, DEOPS, São Paulo, APESP.

18 Ofício do Delegado Auxiliar do DOPS ao Delegado Regional de Polícia de Araraquara, São Paulo, 2/7/1952, n. 50-Z-142-339-B e Informe do Serviço de Informações do Departamento de Ordem Social, São Paulo, 10/5/1972. APESP.

19 Informe n. 2.028/75-DSS, DEOPS, São Paulo, APESP.

20 Informe n. 1.719/76, Prontuário 81.327, DOP, São Paulo, APESP.

21 Informe SS - 4-/468 de 18 de 12/12/1953 do delegado Chefe do Serviço Secreto ao Delegado Regional de Polícia de Araraquara. APESP, 150-Z -142-183-443-3, APESP.

22 Já na década de 1970 foi identificada no mesmo prontuário a proximidade de Clóvis Moura em relação ao PC do B (como colaborador) e de seu dirigente Pedro Pomar, na época jornalista de O Movimento. Em 1980, Clóvis, sua filha Soraya Moura e José Carlos Gianini aparecem associados, no prontuário, ao CIPES (Centro de Intercâmbio de Pesquisa e Estudos Econômicos e Sociais).

23 Ofício do Delegado Auxiliar Diretor do DOPS ao Delegado Regional de Polícia de Araraquara, dossiê 50-Z-142-339-B, APESP.

24 DOPS, Serviço Secreto, Prontuário de 11/06/1952, informe n 1.719/76. Ver especialmente o documento sobre investigações procedidas em Ibitinga, Borborema, Novo Horizonte, São José do Rio Preto, Bálsamo, Catanduva, Tanabi, Cosmorama, Monte Aprazível, Nova Granada e Araraquara em torno das atividades comunistas. (11/6/1952), APESP

25 Sociais. Notícias de Hoje, São Paulo, 10/6/1954 (retalho sem identificação de página). 
Teresa MALATIAN. Professora Titular do Programa de Pós-graduação em História, Faculdade de Ciências Humanas e Sociais, Univiversidade Estadual Paulista - UNESP, campus de Franca. Av. Eufrásia Monteiro Petraglia, 900, 14409-160 Franca, São Paulo, Brasil.

Declaração de Financiamento. A pesquisa que resultou neste artigo contou com financiamento da FAPESP, processo 2016/2011-0.

Recebido em: 27/04/2018

Aceito em: 05/10/2018 